\title{
Giardia agilis: Ultrastructure of the Trophozoites in the Frog Intestine
}

\author{
Maria Inês L Sogayar/ ${ }^{+}$, Elisa Aparecida Gregório* \\ Departamento de Parasitologia *Departamento de Morfologia, Instituto de Biociências, UNESP, \\ Campus de Botucatu, 18618-000 Botucatu, SP, Brasil
}

Intestine samples of Bufo sp. tadpoles with parasitism confirmed for Giardia agilis were studied by transmission electron microscopy. The G. agilis trophozoites were long and thin. The plasma membrane was sometimes undulated and the cytoplasm, adjacent to the dorsal and ventral regions, showed numerous vacuoles. The two nuclei presented prominent nucleoli. The cytoplasm was electron-dense with free ribosomes, glycogen and rough endoplasmic reticulum-like structures. Polyhedral inclusions were observed in the cytoplasm and outside the protozoan; some of these inclusions exhibited membrane disruption. The flagella ultrastructure is typical, with the caudal pair accompanied by the funis. Next to the anterior pair, osmiophilic material was noticed. The ventro-lateral flange was short and thick, supported by the marginal plates that penetrated into its distal extremity; only its distal portion had adjacent osmiophilic filament. The G. agilis trophozoites showed the general subcellular feature of the genus. However, the ventro-lateral flange ultrastructure was an intermediate type between G. muris and G. duodenalis.

Key words: ultrastructure - Giardia agilis - trophozoite

Giardia agilis is an intestinal parasite of tadpoles and adult anuran amphibians. It was first described by Kunstler (1822) and later by Alexeieff (1914), Hegner (1922) and Lavier (1935a, 1942). In vitro growth for this species has not been reported; apparently they do not cause disease in their hosts (Meyer \& Radulescu 1984).

The trophozoites have a narrow and elongated body and the adhesive disc length is about onefifth of the body; the median bodies appear as a single club-shaped rod, as revealed by light microscopy (Kulda \& Nohýnková 1978). Observations on their general morphology were described with scanning electron microscope by Feely and Erlandsen (1985); however the transmission electron microscopic studies could not be found in the literature. In the present investigation, it was described, for the first time, the subcellular structures of the G. agilis trophozoites. The understanding of its ultrastructure may help to determine the systematic relationship of this organism with G. muris and $G$. duodenalis.

\footnotetext{
This work was supported by CNPq (Proc. 407881/84) and FAPESP (Proc. 300107/84).

${ }^{+}$Corresponding author. Fax: +55-14-821.3744. E-mail: parasitologia@laser.com.br

Received 5 September 1997

Accepted 18 February 1998
}

\section{MATERIALS AND METHODS}

Tadpoles of Bufo sp. were collected in the field (Botucatu, SP, Brazil) and maintained in aerated pond water; they were fed with fresh beaten lettuce. The animals were sacrificed by ether inhalation and the small intestine was removed. To confirm the infestation, the intestinal content was smeared on a slide, fixed in Schaudinn's solution, stained by the Heidenhain iron hematoxylin method and examined under a light microscope. Fragments of the small intestines positive for Giardia infestation were fixed in $2.5 \%$ glutaraldehyde buffered with $0.1 \mathrm{M}$ phosphate buffer $\mathrm{pH} 7.3$ and post-fixed in $1 \%$ osmic acid in the same buffer. They were dehydrated in acetone and embedded in Araldite. Ultrathin sections were stained with uranyl acetate and lead citrate and examined with a transmission electron microscope.

\section{RESULTS}

G. agilis trophozoites could be observed either along the intestinal intact mucosa without any image of attachment to the substratum (Fig. 1) or in slight contact with the mucosa microvilli.

The trophozoites presented an adhesive disc composed by a single layer of microtubules linked to each other through thin filaments; each microtubule was associated to an electron-dense fibrous ribbon (Figs 1-4). The disc was bordered by the ventro-lateral flange; in cross section the distal extremity of flange was short and thick (Figs 1, 3, 4). The striated marginal plate was well developed 
and penetrated into its distal extremity; there was a small osmiophilic filament surrounding only its distal portion (Figs 3,4). The two nuclei (Figs 1, 6) were elongated with decondensed chromatin and prominent nucleoli.

The plasma membrane was sometimes undulated and the cytoplasm, adjacent to dorsal and ventral regions, showed numerous vacuoles (Fig. 6).

Free ribosomes and glycogen particles (Figs 3, $7,10)$ were numerous in the cytoplasm. Some trophozoites presented rough endoplasmic reticulumlike structures (Fig. 7). The microtubular structure of the median body could be seen near the adhesive disc. The axonemes of the flagella had the typi- cal microtubular ultrastructural organization (Fig. 5 ); the axonemes of the caudal flagella was accompanied by the funis (Figs 5, 6). Osmiophilic material was detected near the axonemes of anterior flagella (Fig. 3).

Inclusions could be observed in the cytoplasm of some trophozoites (Figs 8-10) as well as outside the protozoan (Fig. 8). These structures appeared as pentagonal and hexagonal bodies measuring $200 \mathrm{~nm}$ in diameter, surrounded by a membranous envelope. They presented either a less electron-dense core limited by a layer of dense material (Figs 8,9$)$ or they may appear to be a very dense core surrounded by a electron lucent area
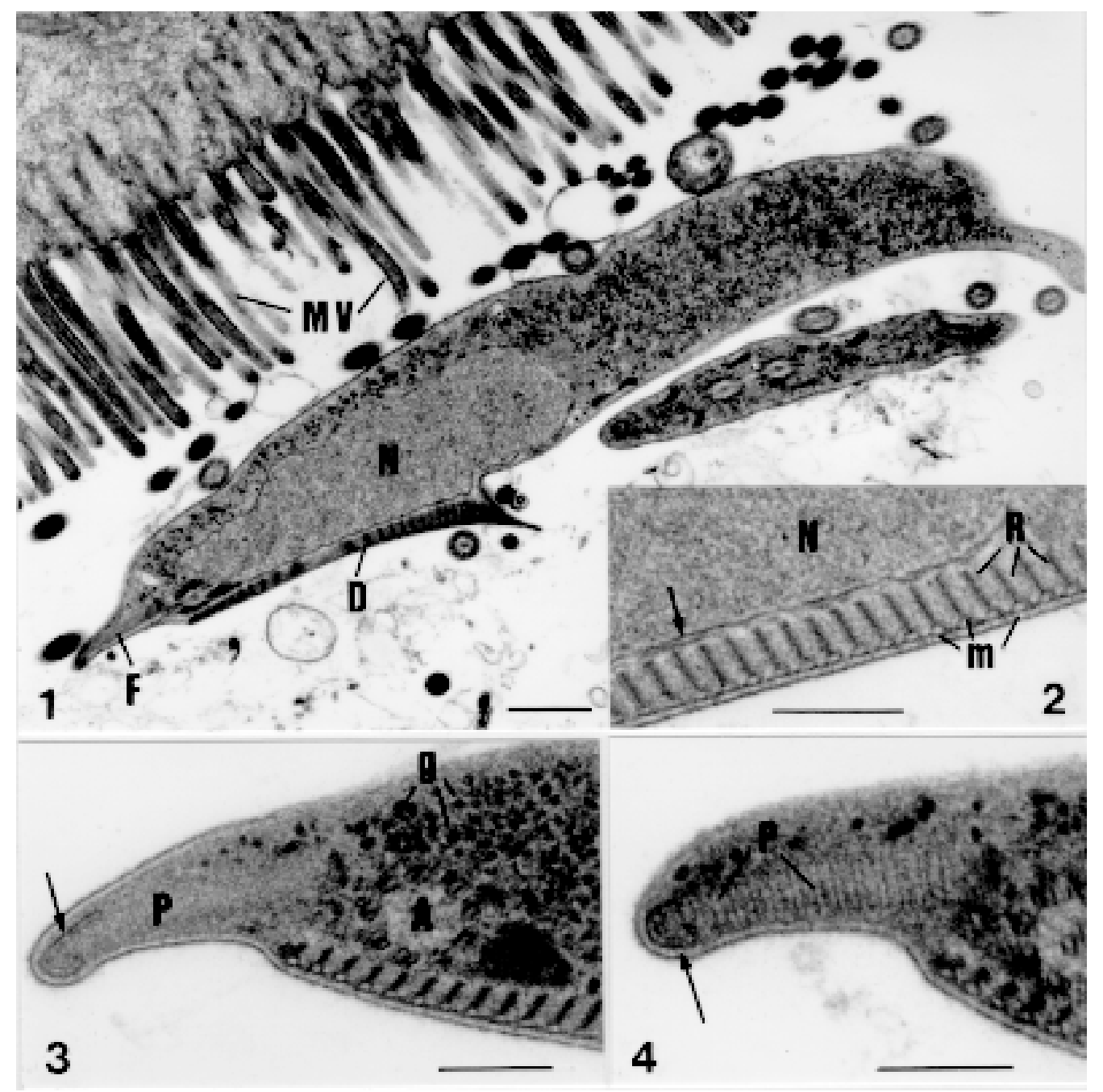

Fig. 1: general aspect of Giardia agilis trophozoites over the intestinal microvilous (MV). Nuclei (N); adhesive disc (D); ventro lateral flange $(\mathrm{F})$. Bar $=0.5 \mathrm{~mm}$. Fig. 2: detail of the throphozoite ventral region. Adhesive disc with microtubule $(\mathrm{m})$ jointed to the endoplasm by fibrous ribbons $(\mathrm{R})$; nucleus $(\mathrm{N})$ and nuclear envelope (arrow). Bar = 0,2 mm. Fig. 3: cross section of the ventro lateral flange. Marginal plate $(\mathrm{P})$ with osmiophilic filament (arrow); dense material $(*)$ adjacent to the flagellar axoneme (A); glycogen particles (g). Bar $=0.2 \mathrm{~mm}$. Fig. 4: detail of the ventro lateral flange. Osmiophilic filament (arrow) surrounding the distal extremity of the striated marginal plate $(\mathrm{P})$. Bar $=0.25 \mathrm{~mm}$. 
(Figs 8,10$)$. The cytoplasm adjacent to these structures also exhibited fragments of membrane (Fig. 8 ) suggesting disruption of some inclusions.

\section{DISCUSSION}

G. agilis is a parasite which has been little morphologically studied since its original description (Lavier 1934, 1935b, Machado Filho 1966). The lack of interest is due to the fact that the pathogenicity of the trophozoite for the amphibian host has never been observed, and this organism was never found parasiting man (Adam 1991).

The ultrastructure of the G. agilis trophozoites observed in the intestine of Bufo sp. confirmed the general morphological description made for this protozoan by light microscope observations (Hegner 1922, Kulda \& Norhýnková 1978), although some features had the proportions altered by the long and slender form of this organism, as observed by Feely and Erlandsen (1985) using the scanning electron microscope (SEM). Our results also showed that the G. agilis trophozoites had the general ultrastructural features of the genus, already described for G. muris and G. duodenalis groups in other animals (for review, see Kulda \& Nohýnková 1978, Adam 1991, Gillin et al. 1996). In this study some relevant aspects of its morphology are discussed, especially those which clearly show the differences when compared to other species.

Feely and Erlandsen (1985) described microvillous-like appendages along the lateral borders in most of the trophozoites isolated from the frog intestinal content. These structures were related to the attachment of the trophozoites to the substratum used for the SEM preparations, an uncoated cover glass. The authors suggested that they could be responsible for the focal contact of the parasites over the mucosa, in answer to the prompt changes of the intestinal flow. It was not possible to detect those appendages in the trophozoite ultrathin sections analyzed in our work; the G. agilis
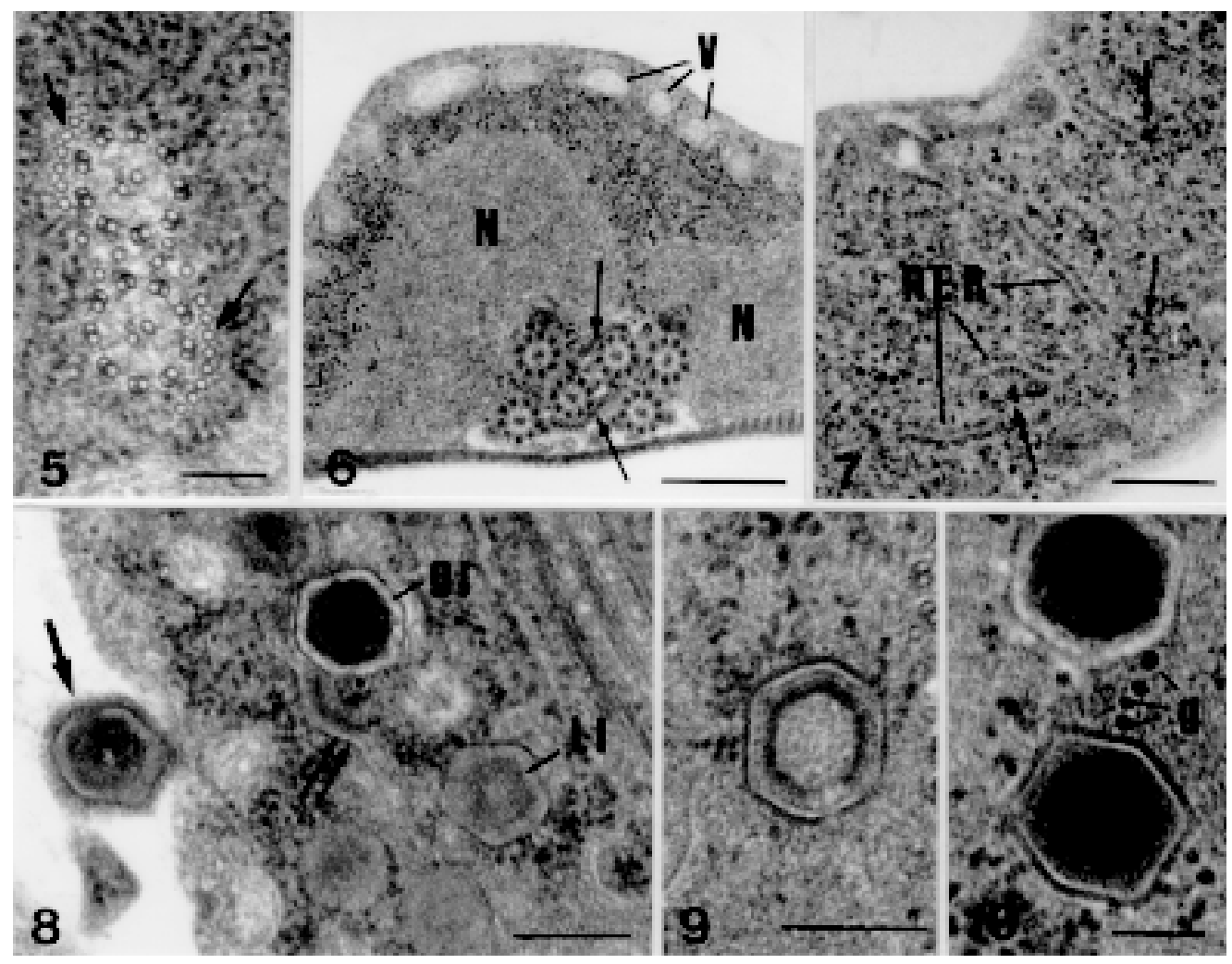

Fig. 5: Giardia agilis funis (arrows) in association with the caudal axonemes. Bar $=0.1 \mathrm{~mm}$. Fig. 6: cross section of the trophozoite. Nuclei $(\mathrm{N})$; vacuoles $(\mathrm{V})$; funis (arrows). Bar $=0.5 \mathrm{~mm}$. Fig. 7: detail of the trophozoite cytoplasm. Rough endoplasmic reticulumlike structures (RER); glycogen particles (arrows). Bar $=0.25 \mathrm{~mm}$. Fig. 8: dorsal region of the trophozoite. Cytoplasm with polihedral inclusions with a dense (DI) or a lucent (LI) core, adjacent to disrupted structures (double arrow). Inclusion outside the protozoan (arrow). Bar $=0.2 \mathrm{~mm}$. Fig. 9: detail of a inclusion with a layer of dense material surrounding a less electron dense core. Bar $=0.2$ $\mathrm{mm}$. Fig. 10: detail of the inclusions with electron dense core; glycogen particles $(\mathrm{g})$. Bar $=0.1 \mathrm{~mm}$. 
surface exhibited only discrete plasma membrane undulations. The influence of the methodology on the morphological characteristics of the G. agilis trophozoites must be taken into account. The only image of adhesion detected was a slight contact of the trophozoites with the mucosa, either by the adhesive disc or to the ventro-lateral flange. The possibility that G. agilis can be pathogenic to their hosts is yet a matter of future investigation, as the frog intestinal mucosa did not show signs of damage.

The G. agilis ventro-lateral flange showed an ultrastructural morphology different from those described for both the G. muris and G. duodenalis trophozoites. The G. duodenalis trophozoite presented short and thick distal extremity of the flange, with a little developed marginal plate; osmiophilic lamella was not present (Kulda \& Norýnková 1978, Sogayar \& Gregório 1989b). In G. muris trophozoites the distal extremity of the flange was narrow and developed. The marginal plate seemed to occupy the whole flange extension and a dense lamella of osmiophilic material accompanying the dorsal surface of the plate was observed (Sogayar \& Gregório 1989b). In G. agilis trophozoites the distal extremity of the flange was short and thick, presenting a well developed marginal plate penetrating into its distal extremity, similar to the $G$. duodenalis type. However there is a small osmiophilic filament accompanying only its distal extremity, as observed in G. muris type. Thus, the pattern of the flange suggested that G. agilis showed an intermediary morphological type between G. muris and G. duodenalis. The significance of the morphological features of the ventro-lateral flange in the taxonomy of the Giardia species were discussed by Sogayar and Gregório (1989b). Our results confirmed the general tendency of the authors to consider the existence of the three morphological groups of Giardia: G. duodenalis and G. muris from mammals, and G. agilis from amphibians (Felice 1952, Kulda \& Nohýnková 1978).

The presence of rough endoplasmic reticulumlike structures in G. agilis suggests that this group may have a system of endomembranous organelles as demonstrated by McCaffery and Gillin (1994) and Attias et al. (1996) in G. lamblia. The use of complementary membrane-enhancing ultrastructure techniques as well as cytochemical methods in the G. agilis preparations may confirm the existence of endomembranes.

The observation of polyhedral structures in the cytoplasm of $G$. agilis trophozoites was a very interesting finding. These structures had similar morphology to those described in G. duodenalis of black rats (Sogayar \& Gregório 1986). Although its nature has not been elucidated, the polyhedral structures observed in G. agilis may represent viral-like particles of c.a. $200 \mathrm{~nm}$, bigger than the viruses or virus-like particles described in Giardia trophozoites by many authors (Feely et al. 1988, Wang \& Wang 1991).

The detection of disrupted membranous envelope in some inclusions suggests a reaction of the host, showing a character of parasitism on this association. Sogayar and Gregório (1986) did not find destruction of the inclusions by G. duodenalis trophozoites; the trophozoites presented electron lucent cytoplasmic area surrounded by the inclusions, suggesting a harmful action of the inclusion on the trophozoite integrity. The significance of the detection of similar structures in the two different groups of Giardia, with differences on the hostparasite relationship need to be elucidated.

As these inclusions were also detected outside the trophozoites, it is interesting to know how they could be internalized by the trophozoites. Sogayar and Gregório (1989a) reported the phagocytosis of bacteria by G. duodenalis trophozoites in black rats. A similar mechanism may not occur in $G$. agilis related with the inclusions, as it was not possible to visualise phagocytic vacuole around the structures.

\section{ACKNOWLEDGEMENTS}

To Mrs Maria Aparecida Ramos, Maria Euleda L Perez and Maria Helena Moreno for technical help. To Mr Nivalde Basso for photographic assistance.

\section{REFERENCES}

Adam RD 1991. The biology of Giardia spp. Microbiol Rev 55: 706-732.

Alexeieff A 1914. Notes protistologiques: VIII - Sur la revision des genres de l'ordre Polymastigina, Blochmann. Zool Anz 44: 193-213.

Attias M, Lanfredi A, De Souza W 1996. Cytochemistry and three dimensional reconstruction, a conjugate approach. Acta Microsc 5: 26-29.

Feely DE, Erlandsen SL 1985. Morphology of Giardia agilis: observation by scanning electron microscopy and interference reflexion microscopy. J Protozool 32: 691-693.

Feely DE, Chase DG, Hardin EL, Erlandsen SL 1988. Ultrastructural evidence for the presence of bacteria, viral-like particles, and mycoplasma-like organisms associated with Giardia spp. J Protozool 35: $151-158$

Felice FP 1952. Studies on the cytology and life history of Giardia from the laboratory rat. Univ Calif Publ Zool 57: 53-146.

Gillin FD, Reiner DS, McCaffery JM 1996. Cell biology of the primitive eukaryote Giardia lamblia. Annu Rev Microbiol 50: 679-705.

Hegner RW 1922. The systematic relationship of Giardia lamblia, Stiles 1915 from man and G. agilis Kunstler, 
1882 from the tadpole. Am J Hyg 2: 435-441.

Kulda J, Nohýnková E 1978. Giardia and Giardiasis, p. 69-138. In JP Kreier, Parasitic Protozoa, Academic Press, New York.

Kunstler J 1822. Sur cinq protozoaires parasites nouveaux. CR Soc Biol Paris 95: 347-349.

Lavier G 1934. Sur les formes kystiques de Giardia varani. Ann Parasitol 13: 56-57.

Lavier G 1935a. Sur la propagation et la durée des infections a Giardia agilis chez les batraciens. CR Soc Biol Paris 120: 21-23.

Lavier G 1935b. Sur la struture du corps parabasal de Giardia agilis. CR Soc Biol Paris 120: 198-200.

Lavier G 1942. Les modalités de l'enkystement chez les flagelles du genre Giardia. CR Soc Biol Paris 136: 67-70.

Machado Filho DA 1966. Giardia agilis Kunstler, 1882 (Mastigophora-Octomitidae) em batráquios (girinos) brasileiros. Atas Soc Biol Rio J 10: 91-94.
McCaffery JM, Gillin FD 1994. Giardia lamblia: ultrastructural basis of protein transport during growth and encystation. Exp Parasitol 79: 220-235.

Meyer EA, Radulescu S 1984. In vitro cultivation of Giardia trophozoites, p. 99-109. In SL Erlandsen, EA Meyer (eds), Giardia and Giardiasis, Plenum Press, New York.

Sogayar MIL, Gregório EA 1986. Cytoplasmic inclusions in Giardia: an electron microscopy study. Ann Trop Med Parasitol 80: 49-52.

Sogayar MIL, Gregório EA 1989a. Uptake of bacteria by trophozoites of Giardia duodenalis (Say). Ann Trop Med Parasitol 83: 63-66.

Sogayar MIL, Gregório EA 1989b. Giardia muris and Giardia duodenalis groups: ultrastructural differences between the trophozoites. Rev Inst Med Trop São Paulo 31: 242-247.

Wang AL, Wang CC 1991. Viruses of parasitic protozoa. Parasitol Today 7: 76-80. 
